Aquaculture

December 2018, Volume 497 Pages 189-199

http://dx.doi.org/10.1016/j.aquaculture.2018.07.059

http://archimer.ifremer.fr/doc/00453/56420/

(c) 2018 Elsevier B.V. All rights reserved.

\title{
Understanding the mechanisms involved in the high sensitivity of Pecten maximus larvae to aeration
}

\author{
Pauletto Marianna ${ }^{1,{ }^{*}}$, Di Camillo Barbara ${ }^{2}$, Miner Philippe ${ }^{3}$, Huvet Arnaud ${ }^{3}$, Quillien Virgile ${ }^{3}$, \\ Milan Massimo ${ }^{1}$, Ferraresso Serena ${ }^{1}$, Pegolo Sara ${ }^{4}$, Patarnello Tomaso ${ }^{1}$, Bargelloni Luca ${ }^{1}$
}

${ }^{1}$ Department of Comparative Biomedicine and Food Science, University of Padova, viale dell'università 16, 35020 Legnaro, Italy

2 Department of Information Engineering, University of Padova, via Gradenigo 6B, 35131 Padova, Italy

${ }^{3}$ Ifremer, UMR LEMAR 6539 UBO-CNRS-Ifremer-IRD, ZI de la Pointe du Diable CS 10070, 29280

Plouzané, France

${ }^{4}$ Department of Agronomy, Food Natural resources, Animals and Environment, University of Padova, viale dell'università 16, 35020 Legnaro, Italy

*Corresponding author : Marianna Pauletto, email address : $\underline{\text { marianna.pauletto@unipd.it }}$

\begin{abstract}
:
Among reared bivalves, some "novel species", such as the great scallop, Pecten maximus, have experienced more difficulty with routine reproduction due to their high sensitivity to biological, chemical, and physical stress during stages of early development. Working with high larval densities requires the use of aeration systems to provide optimal larval suspension and feed distribution. The high susceptibility of the great scallop to aeration in small-volume systems may impose an important limitation in hatchery-based practices. The present study aimed to investigate the processes impacted by aeration in $P$. maximus veliger larvae exposed to continuous aeration in small-volume tanks $(10 \mathrm{~L})$. Aeration appeared as major stressor that was responsible for early mortality among exposed animals (at $96 \mathrm{~h}$ after aeration started, haa) when exposure started 13 days after fertilization. Exposed larvae and controls were collected at 12, 24 and 72 haa, and a total of 18 cDNA libraries, each representing a pool of approximately 7,500 larvae, were sequenced, obtaining 358,817,016 raw reads. RNA-seq data were first used to build a de novo transcriptome assembly, and differential transcript abundance was assessed in exposed and control groups; thus, the molecular mechanisms involved in high sensitivity to aeration were deciphered. More than 2,000 transcripts were differentially expressed between exposed and control larvae across the entire time series $(\log F C>1, F D R<5 \%)$. Functional analysis revealed that transcriptional changes in larvae exposed to aeration mainly involved the genes that regulate digestive activity and energy metabolism, immune defense, inflammation, apoptosis, larval growth, and development. The results of this study demonstrate that, overall, aeration affects the feeding capacity and energy metabolism of larvae, with expected consequences on the animal's fitness, including its swimming efficiency. Aeration also triggered immune responses and apoptosis, which then increased through opportunistic infections. Notably, infections may be a consequence of a bacterial bloom triggered by the first mortality events that occurred in the culture. This study provides insights into the interactions between environmental variables and great scallop larvae physiology, and the results may contribute to the development of strategies for improving larval rearing practices and ensuring long-term sustainability of $P$. maximus aquaculture.
\end{abstract}




\section{Highlights}

- Pecten maximus is highly susceptible to mild aeration, a desirable rearing practice yielding optimal larvae and feed distribution. Water turbulence reduced lipid and carbohydrate metabolism in scallop larvae, thus resulting in delayed growth and development. As a symptom of stress condition, larvae died, exhausted due to continuous swimming and inability to feed. These findings may contribute to develop strategies for improving rearing practices and for long-term sustainability of scallop aquaculture. 


\section{Introduction}

The great scallop, Pecten maximus (Linnaeus, 1758), is a native European bivalve mollusc that lives on the Eastern Atlantic coast between Norway and Spain. P. maximus is a species of great commercial importance, whose meat is highly valued and sought after in the European seafood market (Andersen et al. 2011). Compared with wild fisheries, which account for 55501 tons of harvested scallops, its aquaculture production is relatively small (79 tons in 2015; FAO, 2015) and occurs only in France, Ireland, and Norway. These data largely underestimate the role of scallop aquaculture production, as most hatchery-produced seed is used for restocking natural populations to benefit scallop fisheries (Andersen et al. 2011). To date, hatchery practices have been limited by difficulties mainly related to the larval rearing stages. Despite recent progress in the development of new culturing techniques (Andersen et al. 2011; Holbach et al. 2015; Kesarcodi-Watson et al. 2016), great scallop hatchery production is still unpredictable due to the large variations in larval survival. Therefore, to overcome this hurdle, further research is needed.

Highly variable survival rates are often associated with bacterial infections in $P$. maximus larvae (Nicolas et al. 1996; Lambert and Nicolas 1998; Sandlund et al. 2006; Sandaa et al. 2008). In most cases, however, such infections are caused by the proliferation of opportunistic bacteria, which are favored by larval rearing practices that are mostly based on a static system with periodic water renewals and feeding (Robert et al. 1996; Andersen et al. 2011). To cope with bacterial infections, several strategies have been pursued in bivalve farming. A few hatcheries employ antibiotics; however, this method is an unsustainable practice due to the emergence of resistant bacteria (Dubert et al. 2016). In 1994, the European ban on chloramphenicol, one of the most widely used antibiotics in aquaculture, encouraged the development of different strategies, such as new culture systems and rearing practices (Andersen et al. 2011). Other alternative approaches have been exploited, such as the use of probiotics (Riquelme et al. 1997; Kesarcodi-Watson et al. 2012), antibacterial agents (Torkildsen et al. 2002) and new technical approaches such as flow-through systems (Andersen et 
al. 2000; Sarkis et al. 2006; Merino et al. 2009). Large-scale flow-through systems have been tested in Norwegian hatcheries (Andersen et al. 2000; Magnesen et al. 2006; Andersen et al. 2011) and have shown promising results. However, these larval rearing practices still require optimization, as highly variable productions and relatively low larval yield and density still limit the commercial extension of such systems (Torkildsen and Magnesen 2004; Andersen et al. 2011). In France, smallvolume (5 L) flow-through systems have been effectively developed, at high density, for the oysters Crassostrea gigas (Asmani et al. 2017) and Ostrea edulis (Gonzalez Araya et al. 2012). However, in P. maximus larvae, a similar rearing protocol was attempted but remained unsuccessful (Holbach et al. 2015). Recently, the impact of hydrodynamic factors (e.g., aeration and flow-through) on scallop larval development in small volumes $(5-50 \mathrm{~L})$ of water demonstrated that aeration, which is a practice that provides optimal larval suspension, feed distribution, and possibly oxygenation, has detrimental effects on larval health, even when used in combination with a flow-through system (Holbach et al. 2017). Conversely, flow-through systems in small, flat-bottomed tanks without aeration appear to be a promising technique from day 10 after fertilization for larvae that have been initially treated with antibiotics (Holbach et al. 2017). Overall, the authors of this study argued that the aeration, tank shape, tank volume and water-flow rate were key factors affecting larval development and survival. The effectiveness of flow-through systems in scallop rearing has been previously demonstrated for large-volume (4 700 L) systems (Andersen et al. 2000). Contrary to our results, Andersen et al. (2000) showed that large-volume (300 L) aerated static systems resulted in high survival. Torkildsen and Magnesen (2004) compared the survival observed in a P. maximus production context over several years and under different larval rearing systems, including i) static with water change every two days (batch rearing), ii) static with the addition of antibiotics, and iii) flow-through with and without biological filters. They concluded that only batch rearing with the addition of antibiotics showed high and stable survival rates; however, the authors also specified that this option is not viable in the context of commercial production. 
Though aeration is important to prevent the deposition and concentration of larvae and food on the bottom of the tank and to improve larval growth and development (Helm and Spencer 1972), scallop susceptibility to the rearing method successfully used for oyster larvae in small volumes (10 L) may present an important limitation in hatchery-based practices; moreover, this limitation may possibly hamper the development of high-density commercial-scale production. For this reason, characterizing the molecular response of scallop larvae that are experimentally exposed to aeration is crucial for understanding the problem and represents a first step towards the development of efficient and reliable rearing practices in the aquaculture of this high-value species.

Genomics has been identified as a powerful tool that provides detailed knowledge about bivalve biology (Saavedra and Bachère 2006). Since bivalves are non-model organisms and their genome is characterized by a large amount of repetitive, non-coding regions, bivalve genome sequencing and transcriptome characterization remains challenging. However, recent developments in sequencing technologies have provided new tools for bivalve genomics. In the last decade, high-throughput gene expression techniques, such as DNA microarray and RNA sequencing analyses, have been exploited in bivalves. These techniques have significantly improved our understanding of the molecular mechanisms that regulate the biological processes of bivalve species under physiological conditions (Huan et al. 2012; Pauletto et al. 2014a, 2014b; Moreira et al. 2015; Pauletto et al. 2017) or under the effect of abiotic or biotic stressors, such as osmotic pressure (Meng et al. 2013) or bacterial infections (Li et al. 2013; Allam et al. 2014; Pauletto et al. 2014a). Transcriptomic studies have considerably improved the general knowledge on bivalves and may be applied to help develop more efficient rearing protocols and strategies to enhance the long-term sustainability of bivalve aquaculture.

In the present study, RNA-seq was used to investigate the molecular processes driving the $P$. maximus larval responses to tank aeration in small water volumes $(10 \mathrm{~L})$, and it was postulated that aeration acts as a stressor in this type of system. We focused on veliger larvae because, in bivalves, 
early life stages are typically highly susceptible to both biotic and abiotic stress, and this imposes important bottlenecks that hamper commercial-scale hatchery production (e.g., Luna-González et al. 2002; Merino et al. 2009). Shell size, mortality rate, and gene expression profiles were investigated at 12,24 , and $72 \mathrm{~h}$ after the initiation of aeration as well as in control larvae. Particular emphasis was focused on identifying the transcriptional signatures of stressed versus healthy larvae.

\section{Methods}

\subsection{Rearing procedures and experimental design}

A total of 20 wild broodstocks originating from the bay of Brest (Finistère, France) were collected in February 2013 and conditioned for four weeks at $15^{\circ} \mathrm{C}$ in the Ifremer experimental hatchery at Argenton (France), according to the methods described by Robert and Gérard (1999) and Helm et al. (2004). Spawning was induced on 19 March by increasing the temperature to $20^{\circ} \mathrm{C}$, and eggs were fertilized using the method described in Gruffydd and Beaumont (1970). Briefly, just after the beginning of the spawning process, animals were placed in individual beakers to collect gametes, thus reducing self-fertilization. Oocytes were observed and counted before adding sperm to obtain approximately 10 to 20 spermatozoids/oocyte (at the observation plane of the microscope). After verifying the effectiveness of fertilization at the microscope, eggs were pooled and placed in cylindro-conical tanks $(150 \mathrm{~L})$ for embryogenesis. An oocyte was considered to be fertilized once polar bodies and cell divisions were observed. Two days post-fertilization ( $2 \mathrm{dpf})$, the mean number of "D" larvae (the first veliger phase) was estimated, and approximately $3000000 \pm 150000$ (mean $\pm \mathrm{SD}, \mathrm{n}=3$ ) larvae were collected and moved to the Ifremer facilities in Plouzané (Brittany, France). Upon collection, larvae were placed in two 150-L cylindro-conical tanks and treated with 8 ppm chloramphenicol for $48 \mathrm{~h}$. Chloramphenicol was used to prevent bacterial disturbance, to ensure larvae were in a healthy state before experiments and to ensure that the expected mortalities were linked to the application of aeration. Chloramphenicol is not authorized for use in foodproducing animals in the European Union (e.g., Andersen et al. 2011), and we used it briefly at a 
parsimonious dose for research purposes only. It was administered under strict experimental conditions with appropriate water waste treatment to prevent its environmental release.

Larvae were reared at a mean water temperature of $19^{\circ} \mathrm{C}( \pm 1)$ and a light-dark cycle of $12: 12$. The stability of the room temperature was controlled daily to avoid changes in water temperature. Until $10 \mathrm{dpf}$, larvae were fed a mixture of Pavlova lutheri (20 cells/ $\mu \mathrm{L}$ of tank volume), Tisochrysis lutea (20 cells $/ \mu \mathrm{L}$ of tank volume), and Skeletonema marinoi (10 cells $/ \mu \mathrm{L}$ of tank volume) to ensure 50 cells $/ \mu \mathrm{L}$ were available each day. Starting from $11 \mathrm{dpf}$ until the end of the experiment (i.e., at 27 dpf), larvae were fed a mixture of $P$. lutheri ( 25 cells $/ \mu \mathrm{L}$ of tank volume), T. lutea ( 25 cells $/ \mu \mathrm{L}$ of tank volume), and $S$. marinoi (20 cells $/ \mu \mathrm{L}$ of tank volume) to ensure 70 cells/ $\mu \mathrm{L}$ were available each day. A daily diet comprising similar ratios of the genera Pavlova, Tisochrysis, and Skeletonema was previously tested in P. maximus, and the diet was demonstrated to support optimal growth and metamorphosis rates (Tremblay et al. 2007, Kesarcodi-Watson et al. 2016). At 12 dpf, larvae were collected using a $100-\mu \mathrm{m}$ sieve to discard abnormal and smaller larvae and sorted into a 500-mL cylinder. The total number of larvae was estimated by counting the individuals in three independent water samples $(100 \mu \mathrm{L}$ each). Approximately $2247000 \pm 112350($ mean $\pm \mathrm{SD}, \mathrm{n}=3)$ larvae were counted and divided into 13 tanks that each had a volume of $10 \mathrm{~L}$. To perform the experiment, we estimated that at least 110000 larvae were required for each tank. Based on the total number of larvae estimated in the 500-mL cylinder (2 $247000 \pm 112350$ ), we collected larvae using a micropipette and transferred them into each tank with a fixed water volume; ultimately, each tank contained approximately 110000 animals. Moreover, the rearing density in each tank was 11 larvae/mL. At $13 \mathrm{dpf}$, seven tanks were subjected to gentle aeration, and six tanks without aeration were used as the control tanks. A 100-kPa blower coupled to a dehumidifier was used to generate aeration. Air was filtered through a $0.1-\mu \mathrm{m}$ filter and delivered in each tank with one $1-\mathrm{mL}$ glass pipette with an aperture of $0.9 \mathrm{~mm}$ (Holbach et al. 2017). An aeration rate of $155 \mathrm{~mL} \mathrm{~min}{ }^{-1}$ was applied, as this rate was previously reported to increase mortality (Holbach et al. 2017). In fact, 
at this aeration rate, larvae reared in a static system showed a mortality of $37.5 \%$ at $21 \mathrm{dpf}$; in contrast, cultures reared in the static control conditions showed a low mortality (3.7\%) until the end of the experiment (25 dpf) (Holbach et al. 2017). Similar mortalities were obtained in several unpublished experiments conducted in small-volume tanks by our team. Based on this evidence, we decided to use a static system similar to the one exploited in Holbach et al. (2017). Despite the fact that this rearing method is not the best choice for commercial production efforts, the method represents a relevant system for our scientific aims and required relatively simple facilities; furthermore, this method guaranteed that the observed mortality was due to aeration and not to the static system itself. Nonetheless, whether the effects of aeration depend on the rearing volume has not yet been demonstrated.

\subsection{Larval performances}

The shell length (SL, anterior-posterior distance parallel to the hinge) and survival were estimated for each tank.

Approximately 50 larvae/tank (6 control tanks and 7 experimental tanks) were deposited and fixed on a 24-well plate for SL estimation. SL was measured using image analysis (software Image SXM by the National Institutes of Health) before (i.e., 8 and $12 \mathrm{dpf}$ ) and after the beginning of the aeration stimulus (i.e., 14 and $16 \mathrm{dpf}$ ). SL was measured using an inverted microscope (Leitz Leica DMIL, Wetzlar, Germany) equipped with a Moticam 320 digital camera. Images were captured using the Turbo TV software and analyzed using Image SXM. After shape analysis of the objects appearing in the images, only live and single larvae were retained for the determination of SL. Larvae were considered dead when soft tissues were absent (i.e. empty shell) or partially degraded (i.e. the internal structure of the organs were no longer identifiable) (Nicolas et al. 1996). This operation required the successive use of Image SXM, Excel and Statview software. Three independent samples of approximately 200 larvae/tank were collected using an automatic pipette, and samples were placed on a count plate before being fixed with formaldehyde to 
determine survival. In each tank, survival was estimated visually using an optical microscope, and it was measured as the mean percentage $(n=3)$ of live larvae (before being fixed) of the total number of larvae. The overall group survival at different time points was based on the average survival that was calculated for all tanks of each experimental group $(n=6$ for controls and $n=7$ for exposed larvae). Larvae were considered dead when soft tissues were absent (i.e., empty shell) or partially degraded (i.e., the internal structure of the organs was no longer identifiable) (Nicolas et al. 1996).

\subsection{RNA sequencing experiment}

It is well known that, in moribund animals, gene expression profiles largely reflect generic cell degeneration processes rather than specific responses to environmental stimuli. Therefore, we decided to perform RNA-seq analysis on scallop larvae before the onset of extensive mortality (see arrows in Figure 2). Larvae were then harvested at 12, 24, and $72 \mathrm{~h}$ after the application of aeration stress. Controls were sampled at corresponding time points. After gently mixing the water column, larvae were collected by siphoning a fixed volume of water that corresponded to approximately 15 000 larvae. The collected larvae were filtered using a 100- $\mu \mathrm{m}$ mesh, and they were rinsed directly on the filter with sterilized sea water and distilled water before being transferred into 2-mL tubes through the use of a pipette. Tubes were centrifuged (6 $000 \mathrm{rpm})$, excess water was removed, and 1.5 mL of Extract-all solution (Eurobio, Les Ulis, France) was added. At each sampling time, four tubes were sampled per experimental condition (i.e., one tube $=$ one tank) and then stored at $-80^{\circ} \mathrm{C}$ until RNA isolation. The same four tanks were used for each sampling point.

Three culture replicates per condition and per time point were analyzed. Each culture replicate consisted of approximately 7500 larvae collected from different experimental tanks. Total RNA was extracted from each replicate by using a combined protocol of Extract-all solution (Eurobio) and RNeasy mini kit (Qiagen, Hilden, Germany). Once the aqueous and organic phases were separated using Extract-all, $450 \mu \mathrm{L}$ of the aqueous solution was re-suspended in $350 \mu \mathrm{L}$ of $100 \%$ ethanol and transferred into Qiagen columns. The following steps were conducted as suggested by 
the Qiagen RNeasy protocol and by also including the DNAse treatment (Qiagen). RNA was resuspended in RNase-free water, and concentrations were determined using a NanoDrop spectrophotometer (Thermofisher, Wilmington, USA). RNA quality was assessed using a Bioanalyzer 2100 instrument (Agilent, Waldbronn, Germany). Starting from $1 \mu \mathrm{g}$ of total RNA, 18 tagged non-normalized cDNA libraries (three per time point and per condition) were prepared using the SureSelect Strand-Specific RNA Library Prep for the Illumina Multiplexed Sequencing kit (Agilent) following the manufacturer's instructions and a single-end sequencing $50 \mathrm{bp}$ was conducted on an Illumina Hi-seq 2500 (Genome Center, University of California, Davis). Raw Illumina sequencing data have been deposited in GenBank (SRA) with the accession numbers SRR6312404-SRR6312421. All Illumina reads were analyzed using FastaQC software to assess sequence quality and adapter contamination. To filter out any remaining post-sequencing ribosomal RNA, the local sequence alignment tool SortMeRna 2.0 (Kopylova et al. 2012) was applied against different databases (Rfam 5.8S; Rfam 5S; Silva 16S archaeal, bacterial; Silva 18S eukaryote; Silva 23S archaeal, bacterial; Silva 28S eukaryote). The CLC Genomic Workbench v 7.5 was employed to trim adapters and remove low-quality reads.

\subsection{Transcriptome assembly and annotation}

Transcriptome scaffold assembly was performed using the CLC Genomic Workbench v 7.5 with default parameters; furthermore, the method used all the reads obtained in the present experiment plus additional 50 SE Illumina reads that were acquired in a different project focused on scallop larvae (SRR6313185-SRR6313198), previously obtained 100PE Illumina reads (oocytes and hemocytes) and Roche-454 sequences (pool of adult tissues, larvae, hemocytes and oocytes) (Pauletto et al. 2014a, 2017). These sequences were treated as follows: short 50SE Illumina reads constituted the input data, while long reads obtained through either the 100PE strategy Illumina sequencing or pyrosequencing were considered as guidance. Assembled contigs were then further clustered by running CAP3 twice with the default parameters. Contigs from the final assembly were 
annotated through BLASTX similarity searches conducted against the UniProtKB/SwissProt database and selected protein databases available in the Ensembl Genome Browser, respectively, for Homo sapiens, Danio rerio, Drosophila melanogaster, Caenorhabditis elegans, Strongylocentrotus purpuratus, Capitella teleta, Lottia gigantea, and Crassostrea gigas. Alignments with an e-value of at least 10E-5 were considered significant, and the best hit for each contig was used for annotation. Notably, the protein names used within this manuscript are those inferred from the $C$. gigas database. When a putative transcript function was not found in the $C$. gigas database, the protein names retrieved from the UniProtKB/SwissProt database were used.

\subsection{Mapping and differential expression analysis}

Reads were mapped against the scaffold transcriptome by using the CLC Genomic Workbench v 7.5 (RNA-seq experimental parameters: similarity fraction of 0.8 ; length fraction of 0.9 ; mismatch cost of 2; insertion cost of 3; and deletion cost of 3). Raw counts were further analyzed to evaluate differentially expressed (DE) transcripts between treated and control larvae at the three sampling times. The data over-dispersion (phi parameter) was estimated by using edgeR (Robinson et al. 2010a). Raw data were normalized using the trimmed mean of M-values normalization method (TMM) (Robinson et al. 2010b) and ComBat (Johnson et al. 2007), which is a software that accounts for batch effects (i.e., different sequencing runs). Normalized data were analyzed using a slightly modified version of FunPat (Sanavia et al. 2015). First, FunPat assigns a p-value to each gene based on the Bounded-Area method described in Di Camillo et al. (2007). For each gene, the area $\mathrm{A}$ of the region bounded by the gene transcriptional expression profiles in two experimental conditions (e.g., treatment vs. control) is calculated. A p-value is assigned to A by evaluating its statistical significance against a null hypothesis distribution. To accomplish this, instead of using the available replicates as was done in the original paper, a model of the biological plus technical variability and its dependency on the mean gene expression level was derived using a negative binomial model based on the tag-wise phi estimates obtained using edgeR (Robinson et al. 2010a). 
A heat map of the significant transcripts was constructed by using the mean normalized counts of the three replicates obtained from each experimental group. The heat map was generated through the web tool Heatmapper (Babicki et al. 2016) by using the average linkage clustering technique and the Pearson measurement.

To find the molecular mechanisms putatively affected by aeration, a more systematic, functional interpretation of this list of genes was then obtained through enrichment analysis using the Database for Annotation, Visualization, and Integrated Discovery (DAVID) software (Huang et al. 2009). The "Biological process" (BP) annotation categories were used by setting the gene count equal to 3 and the ease value equal to 0.05 , while for the "KEGG Pathway", the ease value was set to 0.1 . Because the DAVID database contains functional annotation data for a limited number of species, it was necessary to link the $P$. maximus transcripts with sequence identifiers that could be recognized in DAVID. This process was accomplished using the UniProtKB/SwissProt accession IDs that corresponded to each contig. These identifiers were used to define a "gene list" (DE transcripts) and a "background" using the bioinformatic tool DAVID. The background corresponded to all the transcripts that were represented on the newly assembled transcriptome.

To summarize the list of significant BP terms in a scatterplot, the web server REVIGO was employed (Supek et al. 2001) by setting a medium-allowed similarity and using the D. rerio GO terms size.

\subsection{Statistical analyses}

Data normality was verified using the Shapiro-Wilk W test. For SL, a t-test was performed to assess the significant difference between the two groups across time points. Shell Length SL values were expressed as the mean \pm standard deviation (SD). For survival, a Mann-Whitney (Wilcoxon) test was used to assess the significance between the two groups across time points. Differences were considered significant when $\mathrm{p}<0.05$. Survival data were expressed as the mean \pm standard error (SE). Statistical analyses were performed using STATGRAPHICS Centurion XVII v. 17.2.05. 


\section{Results}

\subsection{Larval performances}

Larvae exposed to aeration exhibited a lower growth rate than did the controls (Figure 1); specifically, experimental larvae had a mean SL of 154.26 $\pm 9.5($ mean $\pm S D, n=350)$ and $157.29 \pm$ 9.8 (mean $\pm \mathrm{SD}, \mathrm{n}=350) \mu \mathrm{m}$, at 24 and $72 \mathrm{~h}$ after aeration started (haa), respectively, while the observed mean SLs of the controls were 161.12 $\pm 9.2($ mean $\pm S D, n=300) \mu \mathrm{m}$ at 24 haa and $175.13 \pm 10.4($ mean $\pm \mathrm{SD}, \mathrm{n}=300) \mu \mathrm{m}$ at 72 haa. Differences between the two treatments were statistically significant at both 24 and 72 haa.

As shown in Figure 2, control larvae had high survival (approximately 98.5\%) until 24 dpf, which is when they experienced their first significant mortality event (mean survival: 91.7\%). Conversely, mortality appeared early in exposed larvae, and the most significant losses were reported between $16 \mathrm{dpf}$ (72 haa) and $18 \mathrm{dpf}$ (120 haa). Though at $16 \mathrm{dpf}$ (i.e., the last sampling time), the mean larval survival was approximately similar in the control and exposed larvae (97.6 and $94.5 \%$, respectively), by $18 \mathrm{dpf}$, approximately $70 \%$ of the treated larvae had died. At $22 \mathrm{dpf}$, no surviving larvae were observed. The statistical differences in survival between the two experimental groups are reported in Table 1.

\begin{tabular}{|c|c|c|}
\hline DPF & $\begin{array}{c}\text { Wilcoxon W test } \\
\text { (Aeration vs Control) }\end{array}$ & p-value \\
\hline 14 & 26 & 0.260157 \\
\hline 15 & 20 & $0.00998218(*)$ \\
\hline 16 & 45.5 & $0.00332312(*)$ \\
\hline 18 & 42 & $0.00170268(*)$ \\
\hline 20 & 21 & $0.00752188(*)$ \\
\hline 22 & 21 & $0.00252191(*)$ \\
\hline 24 & 21 & $0.00252191(*)$ \\
\hline 27 & 21 & $0.00252191(*)$ \\
\hline
\end{tabular}

Table 1. Statistical differences in survival. Wilcoxon test $W$ and significance are reported for each sampling times. DPF = days post fertilization; asterisks show when the W test is significant. 


\subsection{De novo transcriptome assembly and functional annotation}

A total of 333596673 reads were obtained and deposited in the SRA archive (SRR6312404SRR6312421). The scaffold reference was assembled using over 780 million Illumina reads and 946556 Roche-454 sequences. The assembly was deposited in TSA under the accession number GGAF00000000. The assembly strategy and statistics are summarized in Table 2 . The putative annotation of the assembled contigs was obtained by sequence similarity. Table 2 reports the number of contigs annotated against the individual databases. The highest percentage of matches was obtained against the two molluscan genomes of Crassostrea gigas and Lottia gigantea. By merging all data, a putative annotation was achieved for 30772 contigs (38\%).

\begin{tabular}{|l|l|}
\hline Assembly strategy (CLC Genomic Workbench) & Total reads \\
\hline Illumina 5OSE reads obtained within the present study (used as input) & 333596673 \\
\hline Illumina 5OSE reads from scallop larvae (used as input) & 216133682 \\
\hline Illumina 10OPE reads from scallop haemocytes (used as guidance) & 207637146 \\
\hline Roche-454 sequences from scallop adult tissues (used as guidance) & 946556 \\
\hline Scaffold transcriptome metrics & \\
\hline Total number of contigs (after CAP3) & 80012 \\
\hline Mean length (bp) & 640.3 \\
\hline Median length (bp) & 420 \\
\hline Max length (bp) & 15090 \\
\hline Min length (bp) & 200 \\
\hline Annotation (database) & $n^{\circ}$ annotated contigs (\%) \\
\hline UniProtKB/SwissProt & 21036 (26\%) \\
\hline Homo sapiens & 20095 (25\%) \\
\hline Danio rerio & 20626 (26\%) \\
\hline Drosophila melanogaster & 16216 (20\%) \\
\hline Caenorhabditis elegans & 14145 (18\%) \\
\hline Strongylocentrotus purpuratus & 21598 (27\%) \\
\hline Capitella teleta & 22889 (29\%) \\
\hline Lottia gigantea & $24976(31 \%)$ \\
\hline Crassostrea gigas & 27842 (35\%) \\
\hline & \\
\hline
\end{tabular}

Table 2. Statistics. Summary of assembly strategy and annotation data. $b p=$ base pair

\subsection{Differential expression analysis}


The differential expression analysis allowed the identification of a total of 2134 transcripts that were significantly regulated by aeration across the three time points (FDR $<0.05)$. Contigs showing a BLASTX best match with a non-metazoan UniProtKB/SwissProt were excluded from the analyses. The statistics (p-value, Area, Rank, and FDR) of the remaining 2073 significant transcripts and putative annotation are reported in Supplementary Table 1. In addition, for each of the six sampling groups (CTRL_12H, AER_12H, CTRL_24H, AER_24H, CTRL_72H, and AER_72H) the mean expression values (i.e., normalized counts), fold change (calculated on mean expression values) and trend of expression of the 2073 significant contigs (i.e., up or down regulation) were calculated (see Supplementary Table 1). Out of the 2073 differentially expressed (DE) transcripts, 49\% were up-regulated in AER_12H and down-regulated in AER_24H and AER_72H (Supplementary Figure S1).

Functional enrichment analysis noted a total of 113 enriched biological processes (BPs) and 10 enriched KEGG pathways (Supplementary Table 2). The enriched BPs and their relevance have been summarized in a scatterplot (Figure 3). Some of the most significant enriched biological processes and the related differentially expressed (DE) transcripts are reported below.

Lipid metabolism. The most significant enriched term, with a fold enrichment (FE) of 2.59, was “lipid metabolic process", which was represented by 30 DE transcripts. Among them, differential expression analysis revealed that apolipoprotein D (APOD) and cytosolic phospholipase A2 group IV family (PLA2G4A) were more expressed in larvae exposed to aeration across all time points, while 1-acylglycerol-3-phosphate O-acyltransferase 9 (AGPAT9 1), was more expressed in the control animals. Most of the remaining DE transcripts involved in lipid metabolism were less expressed in the AER_24H and AER_72H experimental groups. Some examples include fatty acid synthase (FASN), a putative fatty acid elongation protein 3 (ELO3), phospholipase B1 (PLB1), ceramide synthase 6 (CERS6), and lysophosphatidylglycerol acyltransferase 1 and 3 (LPGAT1, LPGAT3). 
Growth and development. The BP "imaginal disc-derived wing morphogenesis" showed an FE of 5.97, with $9 \mathrm{DE}$ transcripts. This term included genes involved in larval morphogenesis, such as cadherin-related tumor suppressor (FAT), furry-like protein (FRY), integrin alpha-PS2, and neuralized E3 ubiquitin protein ligase (NEURL). Additional genes that played crucial roles in larval growth and development were significantly changed after exposure to aeration. A few examples are those represented by dyneins, kinesins, chitin synthase, hemicentin-1 (HEM1), metalloproteinases such as meprins (MEP1A, MEP1B) and disintegrin, and metalloproteinase with thrombospondin domains (ADAMTS).

Carbohydrate metabolism. The BP term "polysaccharide catabolic process" was enriched in larvae under aeration with an FE of 11.85 . This term was essentially represented by five differentially expressed contigs encoding a chitinase or chitotriosidase 1 (CHIT1), which is a digestive enzyme. Similarly, several digestive enzymes were found to be regulated by aeration, such as alpha amylase (AMY) and alpha-L-fucosidase (FUCA), both of which were more expressed in AER_12H and less expressed in AER_24H and AER_72H.

Ten DE transcripts were listed in the enriched term "response to insulin" (FE: 3.86), including the mechanistic target of rapamycin (MTOR) and acetyl-CoA carboxylase alpha (ACACA), which were less expressed in AER_72H.

Immune response. The term "immune response" was enriched 2.76 times, with 12 differentially expressed transcripts. Among them, a contig putatively encoding the complement C8 beta chain (C8B) was more expressed in AER_72H. Peroxidasin (PXDN) was more expressed in AER_12H than in the controls, though it was less expressed in AER_24H and AER_72H than in the controls. A transcript encoding a tumor necrosis factor (ligand) superfamily, member 10 (TRAIL), steadily increased in treated larvae until reaching a maximum expression level at 72 haa. Several DE transcripts were also potentially involved in immune processes, such as the acute-phase proteins (APPs) pregnancy zone protein/alpha-2-macroglobulin (A2M), serum amyloid A2 (SAA2), ceruloplasmin $(\mathrm{CP})$ and its homolog hephaestin $(\mathrm{HEPH})$, and heat shock $70 \mathrm{kDa}$ protein $12 \mathrm{~B}$ 
(HSPA12B), all of which were significantly induced by aeration (at different time points).

Additional transcripts that were significantly more expressed after aeration and that might be relevant in scallop immune responses included interferon regulatory factor 2 (IRF2), interferoninduced protein 44-like (IFI44-like), big defensin (BD), immunoresponsive gene 1 like (IRG1), and tachykinin receptors such as substance-K receptor (TACR2), neuropeptide Y receptor type 4 (NPY4R) and tachykinin-like receptor at 86C (TkR86C). Furthermore, key antioxidant enzymes, such as glutathione peroxidase (GPx), dual oxidase (DUOX) and pantetheinase, were reported as being differentially expressed.

Apoptosis regulation. Apoptosis regulation appeared to be affected by aeration, as demonstrated by baculoviral IAP repeat-containing protein 7B (BIRC7B), two apoptosis inhibitors (UniProtKB/SwissProt annotation: BIRC7A and BIRC3) and ceramide kinase (CERK), whose expression was higher after aeration began.

\section{Discussion}

To date, attempts to culture $P$. maximus larvae have demonstrated that this species is more sensitive than other commercially reared bivalve molluscs. Scallops have displayed more vulnerability to both biotic and abiotic stress than have other bivalve species (e.g., Artigaud et al. 2014a); moreover, rearing practices commonly used in other bivalves are often not effective in the scallop hatchery (e.g., Robert et al. 1996; Holbach et al. 2017). The data provided in our study showed that, when using small-volume (10 L) tanks, $P$. maximus larval development and gene expression were considerably impacted by aeration. Nevertheless, this rearing practice, which provides homogeneous feed and larval distribution, is required for high-density commercial production. Gene expression data and larval performances indicate that aeration modifies the hydrodynamic forces and affects larval feeding capacity, energy metabolism and, ultimately, survival. Overall, aeration appeared to be a severe stress factor and caused delayed development and increased mortality in scallop larvae, as has been recently suggested in other studies (Holbach et al, 2015, 
2017). Holbach et al. (2017) demonstrated that aeration had detrimental effects in small-volume (5

L) systems. Conversely, flow-through systems (without aeration) appeared to be a promising technique, though only at lower densities (10 larvae/mL) than those (e.g., 300 larvae/mL) that were successfully tested for professional purposes in oysters (Da Costa et al. 2016; Robert et al. 2017). Holbach et al. (2017) also demonstrated that coupling a flow-through system with aeration, which may allow for higher larval density, increased $P$. maximus larval mortality, which reinforces the adverse effects of the hydrodynamic forces generated by aeration on this species. However, another study that evaluated scallop larval performances and bacterial loads under different rearing systems showed that high-volume (300 L) static systems aerated through a central drain allowed for significant survival up to $40 \%$ at $17 \mathrm{dpf}$ (Andersen et al. 2000), which is clearly acceptable for production but far from the survival of approximately $90 \%$ that was obtained in our control that was devoted to research purposes. The survival reported in the experiment performed by Andersen et al. (2000) remains exceptional and has also been encountered in French commercial hatcheries. Larval densities and rearing volumes could be the most relevant factors explaining such differences in larval performances. Nonetheless, large variations in the quality of gametes and/or larvae between years and seasons should be considered when interpreting the highly variable performances (Robert and Gerard 1999; Torkildsen and Magnesen 2004; Andersen et al. 2011). This emphasizes the fact that research systems should be carefully tested in the context of aquaculture production conditions. RNA sequencing has been increasingly exploited in bivalve species (e.g., Bjärnmark et al. 2016; Nie et al. 2017; Pauletto et al. 2017), yet the P. maximus transcriptome has been poorly investigated, and the available transcriptional data were retrieved from adult tissues (e.g., Artigaud et al. 2014b, 2015a, 2015b). In the present study, a large number of sequences was obtained from great scallop larvae, and a larval scaffold transcriptome with 80012 contigs was provided; thus, this research significantly increased the available genomic information for this species, especially regarding its sensitive planktonic stage. A total of 30772 contigs (38\%) presented a BLASTX hit in at least one database. The database that had the most sequence similarities with $P$. maximus 
assembled transcripts was Ensembl $C$. gigas, which provided a putative function for 27842 contigs (35\%). While available data on larval transcriptomes remains scarce, the total number of contigs assembled and the annotation percentages were similar to those reported recently for other bivalve tissues (Li et al. 2016; Li et al. 2017; Mun et al. 2017).

Our RNA sequencing data revealed more than 2000 differentially expressed transcripts, reflecting the consequences of hydrodynamic modifications caused by aeration. A functional analysis of these transcripts suggested that larvae exposed to aeration experienced reduced feeding capacity and energy metabolism and, ultimately, an increased bacterial load.

Interestingly, at the molecular level, the early consequence of aeration (12 haa) was a general increase in transcriptional activity, with more than $70 \%$ of differentially expressed (DE) transcripts over-represented in treated animals relative to the controls. Conversely, at 24 haa, treated larvae experienced a strong reduction in mRNA transcription, with most of the DE transcripts being downregulated, especially those involved in carbohydrate metabolism and immune response. This pattern might suggest the establishment of an "acute response" in aerated scallop larvae that is based on increased gene transcription and is rapidly counteracted by a type of gene expression blockage at 24 and $72 \mathrm{~h}$ after the exposure to aeration; this result most likely represents apoptosis, cell death and, ultimately, larval death.

\subsection{Decreased efficiency of lipid metabolism and low level of high-energy storage lipids}

Lipids and fatty acids are essential constituents for successful growth and development, and these structures play a major role in how an organism responds to environmental stress (Hochachka and Somero 2002). In addition to their effects on membrane fluidity (Los and Murata 2004), membrane phospholipids are an important source of bioactive compounds and messengers, such as eicosanoids (Parrish 2009). In the present study, an enzyme involved in the release of eicosanoid precursors (PLA2G4A) was expressed at a higher extent in aerated scallop larvae than in the controls, with an FC greater than 1.5 at 12 and 72 haa. This result may indicate a higher production of eicosanoids in response to aeration, a phenomenon that has already been associated with stressful or energetically 
costly conditions in scallops (Pernet et al. 2005) and other invertebrates (Stanley and Howard 1998).

In addition to membrane lipids, high-energy storage lipids (mainly triacylglycerols and their fatty acids) play an important role in the response of organisms to various environmental factors (Freites et al. 2002; Sangiao-Alvarellos et al. 2003), as they cover the energetic costs needed to maintain homeostasis. Lipid metabolism is important for the breakdown or storage of fats to be used as energy. Interestingly, we found that an enzyme involved in the synthesis of glycerophospholipids and triacylglycerol (AGPAT9 1) was less expressed in aerated larvae. This result may be associated with a low level of high-energy storage lipids due to the stressful environmental conditions. We also found that the majority of the DE transcripts involved in lipid metabolism (e.g., FASN, ELO3, PLB1, and CERS6) were less expressed in the AER_24H and AER_72 groups than in the controls. Stressful conditions caused by aeration may have decreased the efficiency of the lipid metabolic processes, which is a known molecular marker of reduced feeding activity that results in delayed growth.

\subsection{Reduced carbohydrate metabolism and absorption rate}

A complex repertoire of polysaccharide-degrading enzymes have been found in the scallop hepatopancreas (Lyu et al. 2016), and, in the present study, the transcription of several of these enzymes appeared to be affected by aeration. For instance, amylase (AMY) and fucosidase (FUCA) were less expressed in treated larvae than in the controls. These digestive enzymes appeared to respond to aeration early at 12 haa, but their transcription dropped significantly lower than that in the controls at 24 and 72 haa. This result could be indicative of a low assimilation rate in response to aeration. After a first attempt to increase their digestive activity to cope with stressful conditions, treated larvae highly reduced their absorption rate, presumably because water turbulence diminished their food ingestion capacity.

As observed for digestive enzymes, transcripts associated with chitin metabolism (e.g., chitinase, chitin synthase) were up-regulated in AER_12H and down-regulated in AER_24H and AER_72H. 
In previous studies, chitinase activity was reported in C. virginica, M. edulis, and C. angulata crystalline structures (Smucker and Wright 1984; Birkbeck and McHenery 1984; Yang et al. 2015), as well as in $C$. angulata larval stages (Yang et al. 2015). As chitinases are required for the degradation of chitin-containing structures, such as algae, we hypothesize that the depletion of chitinase (CHIT1) mRNA was most likely a signal of reduced digestive function. A chitin synthase type 3 also responded to aeration stress and was up-regulated in AER_12H and down-regulated in AER_24H. Chitin is also a key component in mollusc nacre formation, and chitin deposition in the scallop larval shell might be impacted by aeration. A down regulation of chitin synthases in AER_24H might reflect a breakdown of the mineral deposition process in scallop shell biogenesis. For instance, the C-type lectin perlucin (down-regulated in AER_24H and AER_72H) is an important functional protein that regulates mollusc shell and nacre formation (Lin et al. 2013). Overall, the gene expression of transcripts related to carbohydrate metabolism leads us to suggest that aeration induced hydrodynamic modifications that negatively affected larval ingestion and absorption rates, growth, and development. This result was emphasized by the reduced growth rate observed in treated larvae.

\subsection{Reduced motor activity and growth}

As highlighted by the enrichment analysis, the "microtubule-based movement" was overrepresented within the list of DE transcripts. Remarkably, at the last time point before the occurrence of the first mortality event, several transcripts encoding dyneins and kinesins, which are two important families of motor molecules, were significantly down-regulated in response to the stressful conditions induced by aeration. This result suggests a drop in intracellular transport, which is most likely a key cellular event that eventually leads to larval death. These proteins regulate cellular transport, sort proteins and lipids to various destinations, and control cilia/flagella motility, making these proteins fundamental to cellular morphogenesis and functioning (Hirokawa 1998). Interestingly, reduced transport activity might be associated with an oxidative stress condition that leads to the breakdown of the microtubule cytoskeleton and, in turn, to an increased load of 
aggregated proteins in a cell, which potentially leads to overload and cell death (e.g., Perlson et al. 2010; Fang et al. 2012; Song et al. 2016).

Extracellular matrix (ECM) formation and regulation processes appeared to be significantly affected by the water turbulence generated by aeration, as demonstrated by the enriched KEGG “ECM-receptor interaction" and BPs, such as "cell adhesion" and "extracellular matrix organization". The ECM consists of several structural and functional macromolecules and plays an important role in the maintenance of cell and tissue structures and functions, especially in the presence of mechanical stress (Chiquet 1999; Jean et al. 2011). Nonetheless, ECM directly or indirectly controls cellular activities, such as adhesion, migration, differentiation, proliferation, and apoptosis. A few ECM components have previously been studied in bivalves, and they are believed to be involved in mollusc shell synthesis (Jackson et al. 2010). A gene expression profile similar to those evidenced for collagen transcripts was found for some metalloproteinases (ADAMTS, MEP1A, MEP1B). The fact that the transcription of these ECM-related genes diminished before the larval mass mortality event occurred might be a signal of morphogenesis breakdown and compromised tissue structure and function, which ultimately leads to larval death.

Additional genes that played crucial roles in growth and development appeared to be regulated by aeration. For instance, in AER_72H, a contig encoding a master growth regulator (mTOR), which promotes vertebrate cell proliferation and protein synthesis, was less expressed than in controls. In bivalves, mTOR is a key factor that maintains the balance between energy consumption and cellular development (Clark et al. 2013). The inhibition of mTOR is associated with the suppression of adult rudiment development in sea urchin larvae (Carrier et al. 2015), and this inhibition also resulted in starving conditions in an NRK rat cell culture (Yu et al. 2010). Another interesting enzyme that showed the same trend of expression as that found for mTOR (down-regulation in AER_72H) was a carboxylase that is involved in the biogenesis of long-chain fatty acids (ACAC). Notably, the activity of this enzyme is high when fuel molecules are abundant (Berg et al. 2002). The 
aforementioned trends lead us to hypothesize that aeration induces hydrodynamic modifications that prevent larvae from feeding and growing, resulting in a state of low energy availability.

\subsection{Inflammation and immune response activation}

The variation in the mRNA abundance of several genes known to be involved in inflammation processes and defense mechanisms suggests that the hydrodynamic forces generated by aeration may have triggered an immune response; moreover, this immune response was first against the abiotic stress but was later against the opportunistic pathogens that had established in the culture. Abiotic stressors, such as sub-optimal salinity, high temperature, osmotic pressure and farming practices, have been previously associated with immune response activation and outbreaks of opportunistic diseases in bivalves (Lacoste et al. 2001; Long et al. 2008; Kuchel et al. 2010; Li et al. 2013; Luo et al. 2014). Additionally, high bacterial loads have been previously reported in a flowthrough system coupled with aeration at 17 and $22 \mathrm{dpf}$ when mortality rates were high (Holbach et al. 2017). Moreover, previous experiments conducted at the Ifremer facilities in Brest (Miner P., personal communication) demonstrated that, during aeration, larval mortality started before the bacterial bloom, and opportunistic infections occurred as a consequence of the first mortality event and led to the accumulation of dead larvae at the bottom of the tank. While the bacterial load was not measured in the present study, we may suggest that the scallop larvae died because of aeration and that the dead larvae at the bottom of the tank led to bacterial blooms, which further heightened the detrimental effects of aeration. The immune response would, therefore, be primarily triggered by the physical stress, and the second trigger would be the bacterial infection. This hypothesis is supported by the fact that several of the immune genes that were more expressed after aeration had the highest FC in AER_72H (e.g., acute phase proteins (APPs), big defensin, interferon-related genes) when the first mortality event appeared, and this may have reflected an increase in the immune activity due to the establishment of bacteria. 
Among the most relevant transcriptional changes, we found that several putative $P$. maximus transcripts encoding heat shock proteins (HSPA12A, HSPA12B) and other APPs, which are typically produced in response to stressors, were differentially regulated. Serum amyloid protein SAA2, which has already been identified in some bivalve species (e.g., Qu et al. 2014; Rosani et al. 2016), was up-regulated in AER_72H. Similarly, the expression of immune transcripts coding for the antioxidant protein ceruloplasmin (CP) and the proteinase inhibitor alpha-2-macroglobulin (A2M) was induced by aeration.

In contrast, additional APPs, such as complement $\mathrm{C} 8$, which plays a role in defense and in the removal of immune complexes and apoptotic cells (Canas and Canas 2012), and a pattern recognition receptor (MRC1) were up-regulated in AER_12H and down-regulated in AER_24H. This result may suggest decreased immune competence, tissue regeneration, and homeostasis, which most likely contributed to larval death.

A few interferon-related genes (IRFs) were consistently more expressed after aeration began (e.g., IRF2, IFI44-like). IRFs, initially characterized as key genes in the innate defense against viral infection in vertebrates including fish (Zhang and Gui 2012), control many facets of the innate and adaptive immune responses; additionally, they regulate the development of the immune system itself and are involved in reproduction and morphogenesis (Ozato et al. 2007). In bivalve species, IRF2 and IFI44 have been extensively shown to be involved in the immune response against pathogens (Renault et al. 2011; Huang et al. 2013; Segarra et al. 2014).

\subsection{Apoptosis}

As a result of increased microbial contamination and oxidative stress, the apoptotic pathway also appears to be affected, with apoptosis-related transcripts being regulated. Apoptosis activation was indicated in aerated larvae by the over-expression (significant in AER_72H) of a death receptor (TRAIL), which mediated the initiation of the extrinsic pathway of apoptosis and is generally activated in response to various signals including oxidative stress (Armstrong 2006).

Transcriptional variations also included a few ceramide-related genes (ceramide kinase and 
sphingosine-1-phosphate phosphatase 2). In humans, ceramide is involved in a variety of cellular processes, including differentiation, proliferation, and inflammation (reviewed in Hannun 1994; Ballou et al. 1996), and is also an important regulatory participant of programmed cell death that is induced by members of the TNF superfamily (Cuvillier et al. 1996). In the present study, a putative ceramide kinase (CERK) was up-regulated in aerated larvae across all time points $(\mathrm{FC}>1.5)$. Since CERK converts ceramide to ceramide-1-phosphate, which is a metabolite showing pro-survival and pro-inflammatory actions (Gómez-Muñoz et al. 2010), the up-regulation of CERK in scallop larvae might be a mechanism aimed at dampening the pro-apoptotic effects of ceramide, as previously demonstrated in plants (Bornancin 2011). Similarly, the phosphatase SPP2 was early up-regulated in AER_12H and down-regulated in AER_24H and AER_72H. SPP2 is a transmembrane protein that degrades the bioactive signaling molecule sphingosine 1-phosphate, and remarkably, its expression and activity were found to be transiently up-regulated by inflammatory stimuli (e.g., TNF- $\alpha$ and LPS) in a variety of human cells, indicating this enzyme has a role in the potentiation of cytokine-mediated inflammatory responses (Mechtcheriakova et al. 2007). The gene expression data provided here suggest that the balance between the intracellular levels of ceramide and sphingosine-1-phosphate and their regulatory effects might influence the molecular response of scallop to the environmental stress generated by aeration as well as determine cell fate. In Pacific oysters, ceramide signaling has already been proposed as a key component in the cellular response to environmental changes (Timmins-Schiffman and Roberts 2012).

The inhibition of apoptosis was also highlighted. The expression of two putative apoptosis inhibitors was consistently higher in treated animals than in control animals, while the apoptosis inhibitor BIRC7B was significantly up-regulated in AER_24H and AER_72H. BIRC7 has previously been reported to be increasingly transcribed following heat stress in adult $P$. maximus (Artigaud et al. 2015b). 


\section{Conclusion}

The present study demonstrated that $P$. maximus is highly susceptible to aeration in a small-volume $(10 \mathrm{~L})$ rearing system, which represents the type of system routinely employed in the farming of other bivalves; thus, the present study confirmed that technical issues may limit the commercialscale hatchery production of this species in these types of systems. The application of continuous aeration led to slow shell growth and high larval mortalities. RNA sequencing analysis demonstrated that aeration significantly affected mRNA expression. Scallop larvae initially showed an increase in the transcription of a large set of transcripts as an "acute response" to aeration; however, this was rapidly counteracted by a sort of gene expression blockage at 24 and 72 haa, which most likely represented the first step toward organismal death, which was likely exacerbated by the establishment of opportunistic bacteria. Functional analyses of significant transcripts revealed that aeration resulted in delayed growth and development, as was confirmed by the low shell growth (compared to controls). These results are likely consequences related to changes in the food ingestion rate and lipid and carbohydrate metabolisms. At the same time, larvae stressed by aeration appeared to trigger an immune response. It is likely that the elevated immune response that followed the initial mortality event was associated with the establishment of opportunistic pathogens, whose presence was favored by the accumulation of dead larvae in the tanks. This stress condition increased the apoptosis rate, which compromised the cellular activities and induced larval death due to the reduced ability to feed and to continue actively swimming in the turbulent water. This hypothesis was also recently suggested in oyster larvae reared under aeration (Fuchs et al. 2017). Fuchs and colleagues concluded that water motion most likely made it more difficult for the cilia to handle or retain food particles.

Overall, these findings provide information on the interaction between environmental variables and great scallop physiology, and these results may contribute to developing new strategies that improve rearing practices and the long-term sustainability of $P$. maximus aquaculture. In the future, 
additional studies that linked molecular features to hatchery production yields should explore alternative rearing protocols that mitigate the detrimental effects of aeration (e.g., different tank shape and/or aeration strategy), a practice designed to ensure optimal feed and larval distribution.

\section{References}

Allam, B., Pales Espinosa, E., Tanguy, A., Jeffroy, F., Le Bris, C., Paillard, C., 2014. Transcriptional changes in Manila clam (Ruditapes philippinarum) in response to Brown Ring Disease. Fish Shellfish Immunol. 41, 2-11. https://doi.org/10.1016/j.fsi.2014.05.022

Andersen, S., Burnell, G., Bergh, Ø., 2000. Flow-through systems for culturing great scallop larvae. Aquac. Int. 249-257. https://doi.org/10.1023/A:1009271220868

Andersen, S., Christophersen, G., Magnesen, T. 2011. Spat production of the great scallop (Pecten maximus): A roller coaster. Can J Zool. 89, 579-598. https://doi.org/10.1139/z11-035

Armstrong, J.S., 2006. Mitochondrial membrane permeabilization: The sine qua non for cell death. BioEssays. https://doi.org/10.1002/bies.20370

Artigaud, S., Lacroix, C., Pichereau, V., Flye-Sainte-Marie, J., 2014a. Respiratory response to combined heat and hypoxia in the marine bivalves Pecten maximus and Mytilus spp. Comp.

Biochem. Physiol. -Part A Mol. Integr. Physiol. 175, 135-140.

https://doi.org/10.1016/j.cbpa.2014.06.005

Artigaud, S., Thorne, M.A.S., Richard, J., Lavaud, R., Jean, F., Flye-Sainte-Marie, J., Peck, L.S., Pichereau, V., Clark, M.S., 2014b. Deep sequencing of the mantle transcriptome of the great scallop Pecten maximus. Mar. Genomics 15, 3-4. https://doi.org/10.1016/j.margen.2014.03.006

Artigaud, S., Lacroix, C., Richard, J., Flye-Sainte-Marie, J., Bargelloni, L., Pichereau, V., 2015 a. Proteomic responses to hypoxia at different temperatures in the great scallop (Pecten maximus). PeerJ 3, e871. https://doi.org/10.7717/peerj.871

Artigaud, S., Richard, J., Thorne, M.A.S., Lavaud, R., Flye-Sainte-Marie, J., Jean, F., Peck, L.S., Clark, M.S., Pichereau, V., 2015b. Diciphering the molecular adaptation of the king scallop (Pecten maximus) to heat stress using transcriptomics and proteomics. BMC Genomics 16, 988. https://doi.org/DOI 10.1186/s12864-015-2132-x

Asmani, K., Petton, B., Le Grand, J., Mounier, J., Robert, R., Nicolas, J.-L., 2017. Determination of stocking density limits for Crassostrea gigas larvae reared in flow-through and recirculating aquaculture systems and interaction between larval density and biofilm formation. Aquat. Living Resour 30. https://doi.org/10.1051/alr/2017023

Babicki, S., Arndt, D., Marcu, A., Liang, Y., Grant, J.R., Maciejewski, A., Wishart, D.S., 2016. Heatmapper: web-enabled heat mapping for all. Nucleic Acids Res. 44, W147-W153. https://doi.org/10.1093/nar/gkw419 
Ballou, L.R., Laulederkind, S.J.F., Rosloniec, E.F., Raghow, R., 1996. Ceramide signalling and the immune response. Biochim. Biophys. Acta - Lipids Lipid Metab. https://doi.org/10.1016/00052760(96)00004-5

Berg, J.M., Tymoczko, J.L., Stryer, L., 2002. Biochemistry, 5th ed. W H Freeman, New York.

Birkbeck, T.H., McHenery, J.G., 1984. Chitinase in the mussel, Mytilus edulis (L.). Comp. Biochem. Physiol. Part B Comp. Biochem. 77, 861-865. https://doi.org/10.1016/03050491(84)90325-0

Bjärnmark, N.A., Yarra, T., Churcher, A.M., Felix, R.C., Clark, M.S., Power, D.M., 2016. Transcriptomics provides insight into Mytilus galloprovincialis (Mollusca: Bivalvia) mantle function and its role in biomineralisation. Mar. Genomics 27, 37-45.

https://doi.org/10.1016/j.margen.2016.03.004

Bornancin, F., 2011. Ceramide kinase: The first decade. Cell. Signal. https://doi.org/10.1016/j.cellsig.2010.11.012

Canaas, C.A., Canas, F., 2012. The biological significance of evolution in autoimmune phenomena. Autoimmune Dis. https://doi.org/10.1155/2012/784315

Carrier, T.J., King, B.L., Coffman, J.A., 2015. Gene expression changes associated with the developmental plasticity of sea urchin larvae in response to food availability. Biol. Bull. 228, 171180. https://doi.org/10.1086/BBLv228n3p171

Chiquet, M., 1999. Regulation of extracellular matrix gene expression by mechanical stress. Matrix Biol. 18, 417-426. https://doi.org/10.1016/S0945-053X(99)00039-6

Clark, M.S., Thorne, M.A.S., Amaral, A., Vieira, F., Batista, F.M., Reis, J., Power, D.M., 2013. Identification of molecular and physiological responses to chronic environmental challenge in an invasive species: The Pacific oyster, Crassostrea gigas. Ecol. Evol. 3, 3283-3297. https://doi.org/10.1002/ece3.719

Cuvillier, O., Pirianov, G., Kleuser, B., Vanek, P.G., Coso, O.A., Gutkind, S., Spiegel, S., 1996. Suppression of Ceramide-Mediated Programmed Cell Death by Sphingosine-1-Phosphate. Nature. https://doi.org/10.1038/381800a0

Da Costa, F., Petton, B., Mingant, C., Bougaran, G., Rouxel, C., Quéré, C., Wikfors, G.H., Soudant, P., Robert, R., 2016. Influence of one selected Tisochrysis lutea strain rich in lipids on Crassostrea gigas larval development and biochemical composition. Aquac. Nutr. 22, 813-836.

https://doi.org/10.1111/anu.12301

Di Camillo, B., Toffolo, G., Nair, S.K., Greenlund, L.J., Cobelli, C., 2007. Significance analysis of microarray transcript levels in time series experiments. BMC Bioinformatics 8 . https://doi.org/10.1186/1471-2105-8-S1-S10

Dubert, J., Osorio, C.R., Prado, S., Barja, J.L., 2016. Persistence of Antibiotic Resistant Vibrio spp. in Shellfish Hatchery Environment. Microb. Ecol. 72, 851-860. https://doi.org/10.1007/s00248015-0705-5

Fang, C., Bourdette, D., Banker, G., 2012. Oxidative stress inhibits axonal transport: implications for neurodegenerative diseases. Mol. Neurodegener. 7, 29. https://doi.org/10.1186/1750-1326-7-29 
FAO, Fishery Statistical Collections, Global Aquaculture Production. Online query. http://www.fao.org/fishery/statistics/global-aquaculture-production/en (accessed 16 October 2017).

Freites, L., Fernaández-Reiriz, M.J., Labarta, U., 2002. Fatty acid profiles of Mytilus galloprovincialis (Lmk) mussel of subtidal and rocky shore origin. Comp. Biochem. Physiol. - B Biochem. Mol. Biol. 132, 453-461. https://doi.org/10.1016/S1096-4959(02)00057-X

Fuchs, H.L., Specht, J.A., Adams, D.K., Christman, A.J., 2017. Turbulence induces metabolically costly behaviors and inhibits food capture in oyster larvae, causing net energy loss. J. Exp. Biol. 220, 3419-3431. https://doi.org/10.1242/jeb.161125

Gómez-Munoz, A., Gangoiti, P., Granado, M.H., Arana, L., Ouro, A., 2010. Ceramide-1-phosphate in cell survival and inflammatory signaling. Adv. Exp. Med. Biol. 688, 118-130.

https://doi.org/10.1007/978-1-4419-6741-1_8

Gonzalez Araya, R., Mingant, C., Petton, B., Robert, R., 2012. Influence of diet assemblage on Ostrea edulis broodstock conditioning and subsequent larval development. Aquaculture 364-365, 272-280. https://doi.org/10.1016/j.aquaculture.2012.08.036

Gruffydd, L.D., Beaumont, A.R., 1970. Determination of the optimum concentration of eggs and spermatozoa for the production of normal larvae in Pecten maximus (Mollusca, Lamellibranchia). Helgoländer wissenschaftliche Meeresuntersuchungen 20, 486-497.

https://doi.org/10.1007/BF01609924

Hannun, Y.A., 1994. The sphingomyelin cycle and the second messenger function of ceramide. J. Biol. Chem.

Helm, M.M., Spencer, B.E., 1972. The importance of the rate of aeration in hatchery cultures of the larvae of ostrea edulis 1. ICES J. Mar. Sci. https://doi.org/10.1093/icesjms/34.2.244

Helm, M.M., Bourne, N., Lovatelli, A., 2004. Hatchery culture of bivalves. A practical manual, FAO Fisheries Technical Paper. https://doi.org/10.1017/CBO9781107415324.004

Hirokawa, N., 1998. Kinesin and Dynein Superfamily Proteins and the Mechanism of Organelle Transport. Science 279, 519-26. https://doi.org/10.1126/science.279.5350.519

Hochachka, P.W., Somero, G.N., 2002. Biochemical Adaptation. Oxford University Press.

Holbach, M., Robert, R., Boudry, P., Petton, B., Archambault, P., Tremblay, R., 2015. Scallop larval survival from erythromycin treated broodstock after conditioning without sediment. Aquaculture 437, 312-317. https://doi.org/10.1016/j.aquaculture.2014.12.003

Holbach, M., Robert, R., Miner, P., Mingant, C., Boudry, P., Tremblay, R., 2017. Effects of hydrodynamic factors on Pecten maximus larval development. Aquac. Res. 48, 5463-5471. https://doi.org/10.1111/are.13361

Huan, P., Wang, H., Liu, B., 2012. Transcriptomic Analysis of the Clam Meretrix meretrix on Different Larval Stages. Mar. Biotechnol. 14, 69-78. https://doi.org/10.1007/s10126-011-9389-0

Huang, D.W., Sherman, B.T., Lempicki, R.A., 2009. Systematic and integrative analysis of large gene lists using DAVID bioinformatics resources. Nat. Protoc. 4, 44-57.

https://doi.org/10.1038/nprot.2008.211 
Huang, X.-D., Liu, W.-G., Wang, Q., Zhao, M., Wu, S.-Z., Guan, Y.-Y., Shi, Y., He, M.-X., 2013. Molecular characterization of interferon regulatory factor 2 (IRF-2) homolog in pearl oyster Pinctada fucata. Fish Shellfish Immunol. 34, 1279-1286. https://doi.org/10.1016/j.fsi.2013.02.003

Jackson, D.J., McDougall, C., Woodcroft, B., Moase, P., Rose, R.A., Kube, M., Reinhardt, R., Rokhsar, D.S., Montagnani, C., Joubert, C., Piquemal, D., Degnan, B.M., 2010. Parallel Evolution of Nacre Building Gene Sets in Molluscs. Mol. Biol. Evol. 27, 591-608. https://doi.org/10.1093/molbev/msp278

Jean, C., Gravelle, P., Fournie, J.-J., Laurent, G., 2011. Influence of stress on extracellular matrix and integrin biology. Oncogene 30, 2697-706. https://doi.org/10.1038/onc.2011.27

Johnson, W.E., Li, C., Rabinovic, A., 2007. Adjusting batch effects in microarray expression data using empirical Bayes methods. Biostatistics 8, 118-127.

https://doi.org/10.1093/biostatistics/kxj037

Kesarcodi-Watson, A., Miner, P., Nicolas, J.L., Robert, R., 2012. Protective effect of four potential probiotics against pathogen-challenge of the larvae of three bivalves: Pacific oyster (Crassostrea gigas), flat oyster (Ostrea edulis) and scallop (Pecten maximus). Aquaculture 344-349, 29-34. https://doi.org/10.1016/j.aquaculture.2012.02.029

Kesarcodi-Watson, A., Miner, P., Nicolas, J.L., Asmani, K., Robert, R., 2016. Pathogenic threats and probiotic use in larviculture of the scallop, Pecten maximus. Aquac. Res. 47, 1221-1230. https://doi.org/10.1111/are.12579

Kopylova, E., Noé, L., Touzet, H., 2012. SortMeRNA: Fast and accurate filtering of ribosomal RNAs in metatranscriptomic data. Bioinformatics 28, 3211-3217. https://doi.org/10.1093/bioinformatics/bts611

Kuchel, R.P., Raftos, D.A., Nair, S., 2010. Immunosuppressive effects of environmental stressors on immunological function in Pinctada imbricata. Fish Shellfish Immunol. 29, 930-936. https://doi.org/10.1016/j.fsi.2010.07.033

Lacoste, A., Cian, M.-C. de, Cueff, A., Poulet, S.A., 2001. Noradrenaline and $\alpha$-adrenergic signaling induce the hsp70 gene promoter in mollusc immune cells. J. Cell Sci. 114.

Lambert, C., Nicolas, J.L., 1998. Specific inhibition of chemiluminescent activity by pathogenic vibrios in hemocytes of two marine bivalves: Pecten maximus and Crassostrea gigas. J. Invertebr. Pathol. 71, 53-63. https://doi.org/10.1006/jipa.1997.4707

Li, Q., Zhao, X., Kong, L., 2013. Transcriptomic response to stress in marine bivalves. Invertebr. Surviv. J. 10, 84-93.

Li, H., Zhang, B., Huang, G., Liu, B., Fan, S., Zhang, D., Yu, D., 2016. Differential Gene Expression during Larval Metamorphic Development in the Pearl Oyster, Pinctada fucata, Based on Transcriptome Analysis. Int. J. Genomics 2016. https://doi.org/10.1155/2016/2895303

Li, H., Liu, B., Huang, G., Fan, S., Zhang, B., Su, J., Yu, D., 2017. Characterization of transcriptome and identification of biomineralization genes in winged pearl oyster (Pteria penguin) mantle tissue. Comp. Biochem. Physiol. - Part D Genomics Proteomics 21, 67-76.

https://doi.org/10.1016/j.cbd.2016.12.002 
Lin, J.Y., Ma, K.Y., Bai, Z.Y., Li, J. Le, 2013. Molecular cloning and characterization of perlucin from the freshwater pearl mussel, Hyriopsis cumingii. Gene 526, 210-216.

https://doi.org/10.1016/j.gene.2013.05.029

Long, W.C., Brylawski, B.J., Seitz, R.D., 2008. Behavioral effects of low dissolved oxygen on the bivalve Macoma balthica. J. Exp. Mar. Bio. Ecol. 359, 34-39.

https://doi.org/10.1016/j.jembe.2008.02.013

Los, D.A., Murata, N., 2004. Membrane fluidity and its roles in the perception of environmental signals. Biochim. Biophys. Acta - Biomembr. https://doi.org/10.1016/j.bbamem.2004.08.002

Luna-González, A., Maeda-Martínez, A.N., Sainz, J.C., Ascencio-Valle, F., 2002. Comparative susceptibility of veliger larvae of four bivalve mollusks to a Vibrio alginolyticus strain. Dis. Aquat. Organ. 49, 221-226. https://doi.org/10.3354/dao049221

Luo, Y., Li, C., Landis, A.G., Wang, G., Stoeckel, J., Peatman, E., 2014. Transcriptomic profiling of differential responses to drought in two freshwater mussel species, the giant floater Pyganodon grandis and the pondhorn Uniomerus tetralasmus. PLoS One 9.

https://doi.org/10.1371/journal.pone.0089481

Lyu, Q., Jiao, W., Zhang, K., Bao, Z., Wang, S., Liu, W., 2016. Proteomic analysis of scallop hepatopancreatic extract provides insights into marine polysaccharide digestion. Sci. Rep. 6. https://doi.org/10.1038/srep34866

Magnesen, T., Bergh, Ø., Christophersen, G., 2006. Yields of great scallop, Pecten maximus, larvae in a commercial flow-through rearing system in Norway. Aquac. Int. 14, 377-394. https://doi.org/10.1007/s10499-005-9039-5

Mechtcheriakova, D., Wlachos, A., Sobanov, J., Kopp, T., Reuschel, R., Bornancin, F., Cai, R., Zemann, B., Urtz, N., Stingl, G., Zlabinger, G., Woisetschlager, M., Baumruker, T., Billich, A., 2007. Sphingosine 1-phosphate phosphatase 2 is induced during inflammatory responses. Cell. Signal. 19, 748-760. https://doi.org/10.1016/j.cellsig.2006.09.004

Meng, J., Zhu, Q., Zhang, L., Li, C., Li, L., She, Z., Huang, B., Zhang, G., 2013. Genome and Transcriptome Analyses Provide Insight into the Euryhaline Adaptation Mechanism of Crassostrea gigas. PLoS One 8. https://doi.org/10.1371/journal.pone.0058563

Merino, G., Uribe, E., Soria, G., von Brand, E., 2009. A comparison of larval production of the northern scallop, Argopecten purpuratus, in closed and recirculating culture systems. Aquac. Eng. 40, 95-103. https://doi.org/10.1016/j.aquaeng.2008.11.002

Moreira, R., Pereiro, P., Canchaya, C., Posada, D., Figueras, A., Novoa, B., 2015. RNA-Seq in Mytilus galloprovincialis: comparative transcriptomics and expression profiles among different tissues. BMC Genomics 16, 728. https://doi.org/10.1186/s12864-015-1817-5

Mun, S., Kim, Y.-J., Markkandan, K., Shin, W., Oh, S., Woo, J., Yoo, J., An, H., Han, K., 2017. The Whole-Genome and Transcriptome of the Manila Clam (Ruditapes philippinarum). Genome Biol. Evol. 9, 1487-1498. https://doi.org/10.1093/gbe/evx096

Nicolas, J.L., Corre, S., Gauthier, G., Robert, R., Ansquer, D., 1996. Bacterial problems associated with scallop Pecten maximus larval culture. Dis. Aquat. Org. 27, 67-76.

https://doi.org/10.3354/dao027067 
Nie, H., Jiang, L., Chen, P., Huo, Z., Yang, F., Yan, X., 2017. High throughput sequencing of RNA transcriptomes in Ruditapes philippinarum identifies genes involved in osmotic stress response. Sci. Rep. 7. https://doi.org/10.1038/s41598-017-05397-8

Ozato, K., Tailor, P., Kubota, T., 2007. The interferon regulatory factor family in host defense: mechanism of action. J. Biol. Chem. 282, 20065-9. https://doi.org/10.1074/jbc.R700003200

Parrish, C.C., 2009. Essential fatty acids in aquatic food webs, in: Arts, M.T., Brett, M.T., Kainz, M. (Eds.), Lipids in Aquatic Ecosystems. Springer, New York, pp. 309-326.

Pauletto, M., Milan, M., Moreira, R., Novoa, B., Figueras, A., Babbucci, M., Patarnello, T., Bargelloni, L., 2014a. Deep transcriptome sequencing of Pecten maximus hemocytes: A genomic resource for bivalve immunology. Fish Shellfish Immunol. 37, 154-165.

https://doi.org/10.1016/j.fsi.2014.01.017

Pauletto, M., Milan, M., De Sousa, J.T., Huvet, A., Joaquim, S., Matias, D., Leitão, A., Patarnello, T., Bargelloni, L., 2014b. Insights into molecular features of Venerupis decussata oocytes: A microarray-based study. PLoS One 9. https://doi.org/10.1371/journal.pone.0113925

Pauletto, M., Milan, M., Huvet, A., Corporeau, C., Suquet, M., Planas, J. V., Moreira, R., Figueras, A., Novoa, B., Patarnello, T., Bargelloni, L., 2017. Transcriptomic features of Pecten maximus oocyte quality and maturation. PLoS One 12. https://doi.org/10.1371/journal.pone.0172805

Perlson, E., Maday, S., Fu, M. meng, Moughamian, A.J., Holzbaur, E.L.F., 2010. Retrograde axonal transport: Pathways to cell death? Trends Neurosci.

https://doi.org/10.1016/j.tins.2010.03.006

Pernet, F., Bricelj, V.M., Parrish, C.C., 2005. Effect of varying dietary levels of $\omega 6$ polyunsaturated fatty acids during the early ontogeny of the sea scallop, Placopecten magellanicus. J. Exp. Mar. Bio. Ecol. 327, 115-133. https://doi.org/10.1016/j.jembe.2005.06.008

Qu, F., Xiang, Z., Yu, Z., 2014. The first molluscan acute phase serum amyloid A (A-SAA) identified from oyster Crassostrea hongkongensis: Molecular cloning and functional characterization. Fish Shellfish Immunol. 39, 145-151. https://doi.org/10.1016/j.fsi.2014.05.013

Renault, T., Faury, N., Barbosa-Solomieu, V., Moreau, K., 2011. Suppression substractive hybridisation (SSH) and real time PCR reveal differential gene expression in the Pacific cupped oyster, Crassostrea gigas, challenged with Ostreid herpesvirus 1. Dev. Comp. Immunol. 35, 725735. https://doi.org/10.1016/j.dci.2011.02.004

Riquelme, C., Araya, R., Vergara, N., Rojas, A., Guaita, M., Candia, M., 1997. Potential probiotic strains in the culture of the Chilean scallop Argopecten purpuratus (Lamarck, 1819). Aquaculture 154, 17-26. https://doi.org/10.1016/S0044-8486(97)00043-4

Robert, R., Miner, P., Nicolas, J.L., 1996. Mortality control of scallop larvae in the hatchery. Aquac. Int. 4, 305-313.

Robert, R., Gérard, A., 1999. Bivalve hatchery technology: The current situation for the Pacific oyster Crassostrea gigas and the scallop Pecten maximus in France. Aquat. Living Resour. https://doi.org/10.1016/S0990-7440(99)80021-7 
Robert, R., Vignier, J., Petton, B., 2017. Influence of feeding regime and temperature on development and settlement of oyster Ostrea edulis (Linnaeus, 1758) larvae. Aquac. Res. 48, 47564773. https://doi.org/10.1111/are.13297

Robinson, M.D., McCarthy, D.J., Smyth, G.K., 2010a. edgeR: a Bioconductor package for differential expression analysis of digital gene expression data. Bioinformatics 26, 139-140. https://doi.org/btp616 [pii]ไr10.1093/bioinformatics/btp616

Robinson, M.D., Oshlack, A., 2010b. A scaling normalization method for differential expression analysis of RNA-seq data. Genome Biol. 11, R25. https://doi.org/10.1186/gb-2010-11-3-r25

Rosani, U., Domeneghetti, S., Gerdol, M., Franzoi, M., Pallavicini, A., Venier, P., 2016. Serum amyloid A in marine bivalves: An acute phase and innate immunity protein. Dev. Comp. Immunol. 59, 136-144. https://doi.org/10.1016/j.dci.2016.01.019

Saavedra, C., Bachère, E., 2006. Bivalve genomics. Aquaculture. https://doi.org/10.1016/j.aquaculture.2006.02.023

Sanavia, T., Finotello, F., Di Camillo, B., 2015. FunPat: function-based pattern analysis on RNAseq time series data. BMC Genomics 16, S2. https://doi.org/10.1186/1471-2164-16-S6-S2

Sandaa, R.A., Brunvold, L., Magnesen, T., Bergh, Ø., 2008. Monitoring the opportunistic bacteria Pseudoalteromonas sp. LT-13 in a great scallop, Pecten maximus hatchery. Aquaculture 276, 14 21. https://doi.org/10.1016/j.aquaculture.2008.02.007

Sandlund, N., Torkildsen, L., Magnesen, T., Mortensen, S., Bergh, Ø., 2006.

Immunohistochemistry of great scallop Pecten maximus larvae experimentally challenged with pathogenic bacteria. Dis. Aquat. Organ. 69, 163-173. https://doi.org/10.3354/dao069163

Sangiao-Alvarellos, S., Laiz-Carrion, R., Guzman, J.M., Del Rio, M.P.M., Miguez, J.M., Mancera, J.M., Soengas, J.L., 2003. Acclimation of S. auratato various salinities alters energy metabolism of osmoregulatory and nonosmoregulatory organs. Am. J. Physiol. - Regul. Integr. Comp. Physiol. 285, R897-R907. https://doi.org/10.1152/ajpregu.00161.2003

Sarkis, S., Helm, M., Hohn, C., 2006. Larval rearing of calico scallops, Argopecten gibbus, in a flow-through system. Aquac. Int. 14, 527-538. https://doi.org/10.1007/s10499-006-9052-3

Segarra, A., Baillon, L., Tourbiez, D., Benabdelmouna, A., Faury, N., Bourgougnon, N., Renault, T., 2014. Ostreid herpesvirus type 1 replication and host response in adult Pacific oysters, Crassostrea gigas. Vet. Res. 45. https://doi.org/10.1186/s13567-014-0103-X

Smucker, R.A., Wright, D.A., 1984. Chitinase activity in the crystalline style of the american oyster Crassostrea virginica. Camp. Biochem. Physiol 77, 239-241. https://doi.org/10.1016/03009629(84)90054-9

Song, Q., Zheng, P., Qiu, L., Jiang, X., Zhao, H., Zhou, H., Han, Q., Diao, X., 2016. Toxic effects of male Perna viridis gonad exposed to BaP, DDT and their mixture: A metabolomic and proteomic study of the underlying mechanism. Toxicol. Lett. 240, 185-195.

https://doi.org/10.1016/j.toxlet.2015.10.031

Stanley, D.W., Howard, R.W., 1998. The Biology of Prostaglandins and Related Eicosanoids in Invertebrates: Cellular, Organismal and Ecological Actions. Integr. Comp. Biol. 38, 369-381. https://doi.org/10.1093/icb/38.2.369 
Supek, F., Bošnjak, M., Škunca, N., Šmuc, T., 2011. Revigo summarizes and visualizes long lists of gene ontology terms. PLoS One 6. https://doi.org/10.1371/journal.pone.0021800

Timmins-Schiffman, E., Roberts, S., 2012. Characterization of genes involved in ceramide metabolism in the Pacific oyster (Crassostrea gigas). BMC Res. Notes 5, 502.

https://doi.org/10.1186/1756-0500-5-502

Torkildsen, L., Coyne, R., Samuelsen, O.B., Magnesen, T., Bergh, Ö., 2002. Treatment of the early life stages of scallop (Pecten maximus) with antimicrobial agents; searching for an alternative to chloramphenicol. Aquac. Int. 10, 399-409. https://doi.org/10.1023/A:1023347020675

Torkildsen, L., Magnesen, T., 2004. Hatchery production of scallop larvae (Pecten maximus) Survival in different rearing systems. Aquac. Int. 12, 489-507.

https://doi.org/10.1023/B:AQUI.0000042143.53903.21

Tremblay, R., Cartier, S., Miner, P., Pernet, F., Quéré, C., Moal, J., Muzellec, M.L., Mazuret, M., Samain, J.F., 2007. Effect of Rhodomonas salina addition to a standard hatchery diet during the early ontogeny of the scallop Pecten maximus. Aquaculture 262, 410-418.

https://doi.org/10.1016/j.aquaculture.2006.10.009

Yang, B., Zhang, M., Li, L., Pu, F., You, W., Ke, C., 2015. Molecular analysis of atypical family 18 chitinase from Fujian oyster Crassostrea angulata and its physiological role in the digestive system. PLoS One 10. https://doi.org/10.1371/journal.pone.0129261

Yu, L., McPhee, C.K., Zheng, L., Mardones, G.A., Rong, Y., Peng, J., Mi, N., Zhao, Y., Liu, Z., Wan, F., Hailey, D.W., Oorschot, V., Klumperman, J., Baehrecke, E.H., Lenardo, M.J., 2010.

Termination of autophagy and reformation of lysosomes regulated by mTOR. Nature 465, 942-946. https://doi.org/10.1038/nature09076

Zhang, Y.-B., Gui, J.-F., 2012. Molecular regulation of interferon antiviral response in fish. Dev. Comp. Immunol. 38, 193-202. https://doi.org/10.1016/j.dci.2012.06.003 


\section{Figures}

Figure 1. Shell length. Mean shell length $(\mu \mathrm{m})$ and standard deviation (SD) of larvae exposed to aeration $(\mathrm{n}=350)$ and control larvae $(\mathrm{n}=300) .{ }^{*}=\mathrm{p}$-value $<0.00000001$

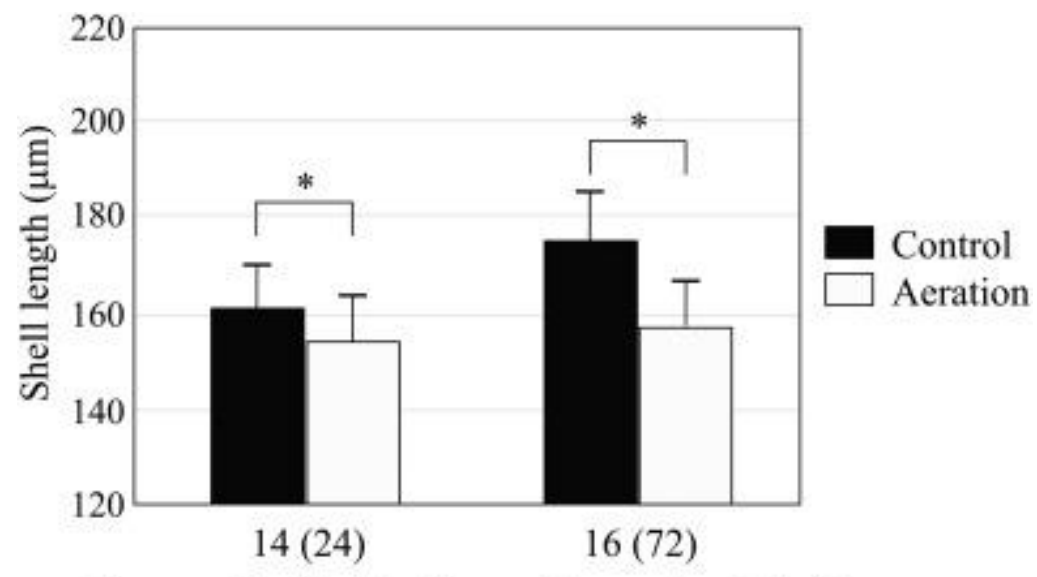

Days post fertilization (hours after aeration started)

Figure 2. Survival. Mean survival (percentage of live larvae on total number of counted larvae) and standard error (SE) of larvae exposed to aeration and control larvae $(n=6$ for control and $n=7$ for exposed larvae). Arrows show when sampling for gene expression analysis was performed.

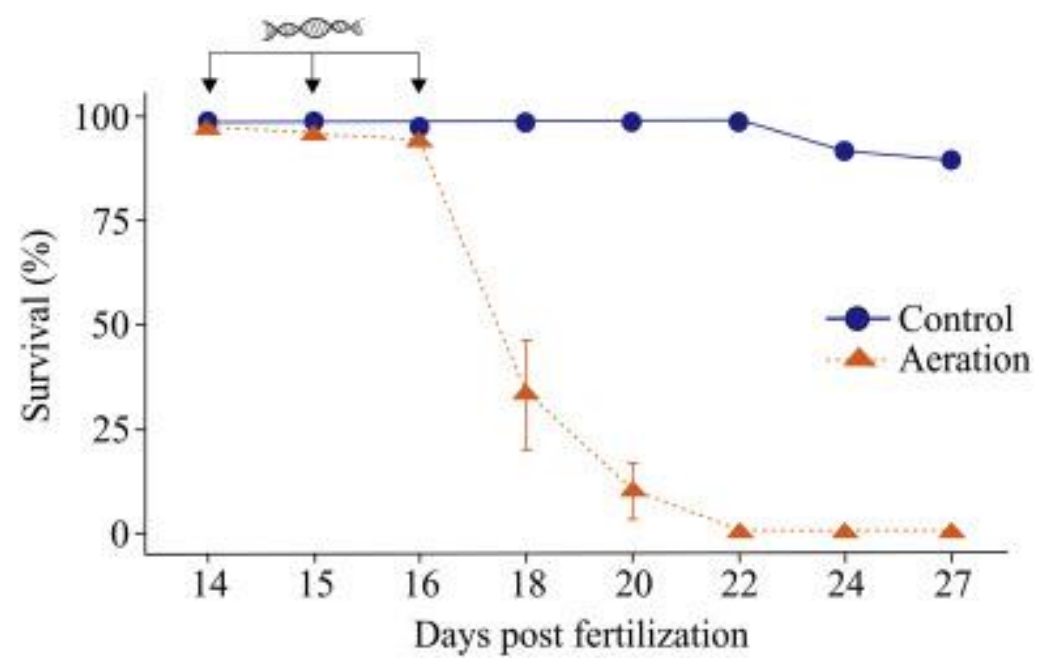

Figure 3. Scatterplot of the significant BP terms. The scatterplot shows the cluster representatives (i.e. terms remaining after the redundancy reduction) in a two dimensional space derived by applying multidimensional scaling to a matrix of the GO terms' semantic similarities. More semantically similar GO terms are closer in the plot. Bubble color indicates the $\log _{10} \mathrm{p}$-value 
(see the legend in upper right-hand corner); size indicates the frequency of the GO term in the underlying GO annotation database (bubbles of more general terms are larger).

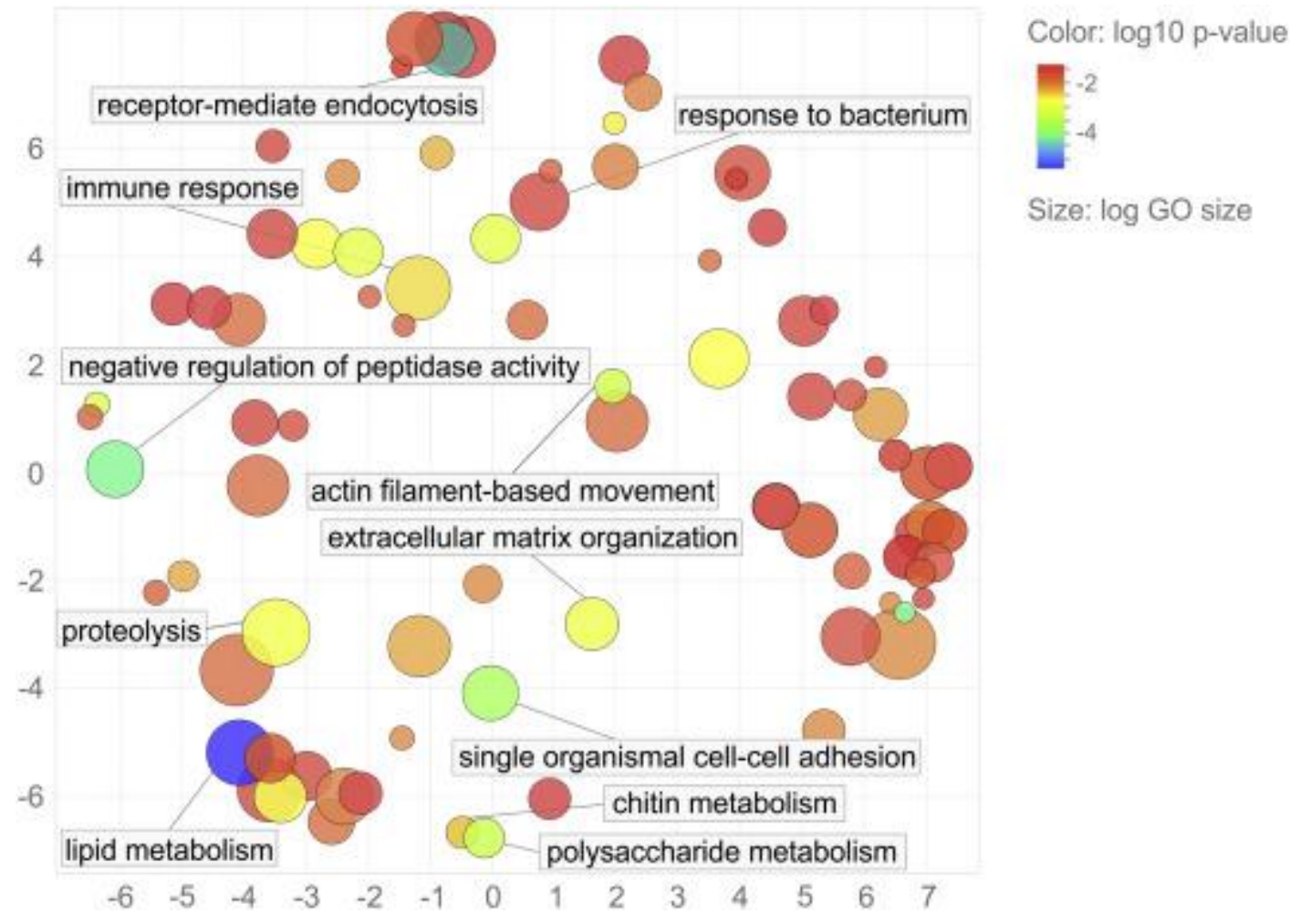




\section{Supplementary material captions}

Figure S1. Expression-based heat map of differentially expressed transcripts. A table with number and percentage of transcripts showing specific trend of expression was reported below the heat map.
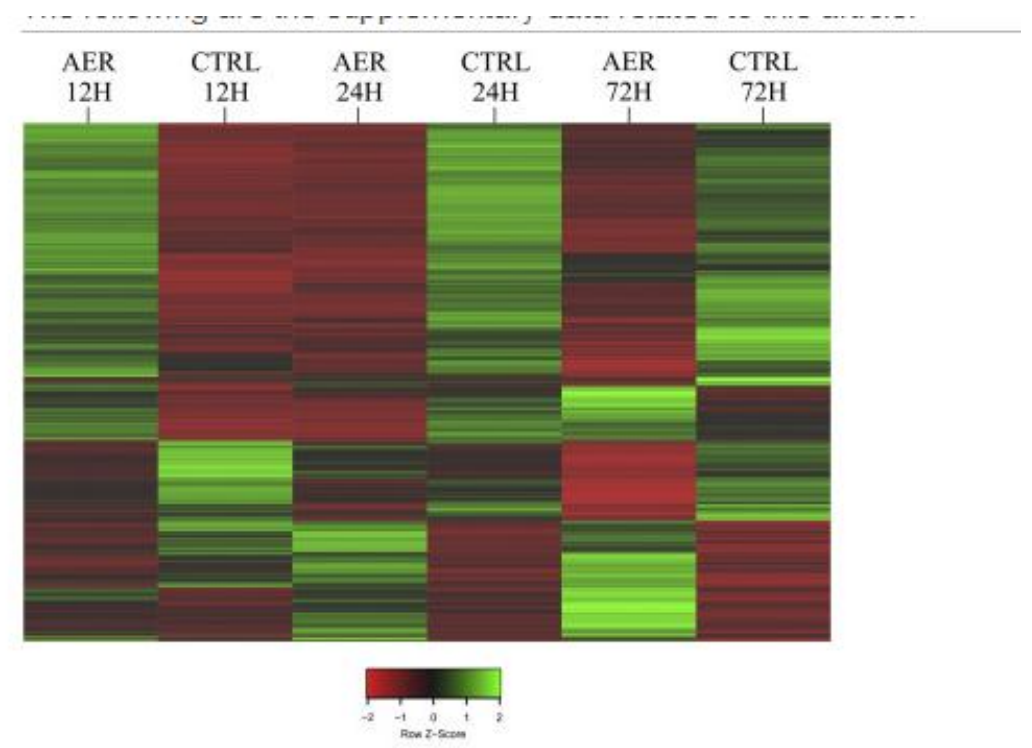

\begin{tabular}{|l|l|}
\hline Expression trend & Number of genes \\
\hline DOWN_12h/DOWN_24h/DOWN_72h & $204(10 \%)$ \\
\hline DOWN_12h/DOWN_24h/UP_72h & $4(10 \%)$ \\
\hline DOWN 12h/UP_24h/DOWN_72h & $132(6 \%)$ \\
\hline DOWN 12h/UP_24h/UP_72h & $290(14 \%)$ \\
\hline UP_12h/DOWN_24h/DOWN_72h & $1008(49 \%)$ \\
\hline UP_12h/DOWN_24h/UP_72h & $219(11 \%)$ \\
\hline UP_12h/UP_24h/DOWN_72h & $16(1 \%)$ \\
\hline UP_12h/UP_24h/UP_72h & $200(10 \%)$ \\
\hline
\end{tabular}

Table S1. Differential expression analysis. The table shows the 2073 significant transcripts with their putative protein annotation. EdgeR statistics (p-value, Area, Rank, and FDR) are also reported. In addition, for each of the six sampling groups (CTRL_12H, AER_12H, CTRL_24H, AER_24H, CTRL_72H, and AER_72H) the mean expression values (i.e., normalized counts), fold change (calculated on mean expression values) and trend of expression of the 2073 significant contigs (i.e., up or down regulation) are reported. 
Table S2. Functional enrichment. DAVID functional enrichment analysis performed on differentially expressed genes. Categories, terms, gene counts, $\mathrm{p}$-values, genes IDs and fold enrichments are reported. 


\section{Author contributions}

M.P., P.M. and A.H. conceived the study. M.P., P.M. and V.Q. set up the hatchery experiments, fed animals and collected samples for the gene expression study. M.P. and P.M. assessed shell growth and mortality rates. M.P. and S.P. isolated scallop RNA. M.P. and S.F. constructed the RNA-seq libraries. M.P. carried out the transcriptome assembly. B.D. set up the differential expression analysis while M.P. analysed the gene expression data. M.M. performed the newly assembled transcriptome annotation. A.H. and L.B. oversaw the gene expression data analysis. M.P. drafted the paper. A.H., L.B. and T.P. participated in data interpretation and in the manuscript writing. All authors read, amended and approved the final manuscript. 


\section{Funding sources}

This work was supported by the EU Project REPROSEED (FP 7-KBBE-2009-1-2-11). 